\title{
Identification of transcription-factor genes expressed in the Arabidopsis female gametophyte
}

\author{
Dongfang Wang ${ }^{1}$, Changqing Zhang 1,3, David J Hearn 1,4, II-Ho Kang 1,2,5, Jayson A Punwani2,6, Megan I Skaggs', \\ Gary N Drews ${ }^{2}$, Karen S Schumaker*1 and Ramin Yadegari*1
}

\begin{abstract}
Background: In flowering plants, the female gametophyte is typically a seven-celled structure with four cell types: the egg cell, the central cell, the synergid cells, and the antipodal cells. These cells perform essential functions required for double fertilization and early seed development. Differentiation of these distinct cell types likely involves coordinated changes in gene expression regulated by transcription factors. Therefore, understanding female gametophyte cell differentiation and function will require dissection of the gene regulatory networks operating in each of the cell types. These efforts have been hampered because few transcription factor genes expressed in the female gametophyte have been identified. To identify such genes, we undertook a large-scale differential expression screen followed by promoter-fusion analysis to detect transcription-factor genes transcribed in the Arabidopsis female gametophyte.

Results: Using quantitative reverse-transcriptase PCR, we analyzed 1,482 Arabidopsis transcription-factor genes and identified 26 genes exhibiting reduced mRNA levels in determinate infertile 1 mutant ovaries, which lack female gametophytes, relative to ovaries containing female gametophytes. Spatial patterns of gene transcription within the mature female gametophyte were identified for 17 transcription-factor genes using promoter-fusion analysis. Of these, ten genes were predominantly expressed in a single cell type of the female gametophyte including the egg cell, central cell and the antipodal cells whereas the remaining seven genes were expressed in two or more cell types. After fertilization, 12 genes were transcriptionally active in the developing embryo and/or endosperm.

Conclusions: We have shown that our quantitative reverse-transcriptase PCR differential-expression screen is sufficiently sensitive to detect transcription-factor genes transcribed in the female gametophyte. Most of the genes identified in this study have not been reported previously as being expressed in the female gametophyte. Therefore, they might represent novel regulators and provide entry points for reverse genetic and molecular approaches to uncover the gene regulatory networks underlying female gametophyte development.
\end{abstract}

\section{Background}

The female gametophyte is an integral component of the plant life cycle and plays an essential role in plant reproduction. In most angiosperms including Arabidopsis, the female gametophyte (also called the embryo sac) typically consists of an egg cell, a central cell, two synergid cells, and three antipodal cells [1,2]. During double fertilization, the pollen tube penetrates one of the synergid cells and releases two sperm cells, which fuse with the egg cell and the central cell to give rise to the embryo and the endosperm, respectively [3]. The embryo forms the next

* Correspondence: schumake@ag.arizona.edu, yadegari@email.arizona.edu School of Plant Sciences, University of Arizona, Tucson, Arizona 85721-0036, USA

Full list of author information is available at the end of the article generation while the endosperm functions to support embryo development and/or seedling development after seed germination [4-6]. Normal seed development depends on the proper differentiation and functions of the central cell and the egg cell [1,2,7-20]. Although the synergid cells do not directly contribute to the development of the seed after fertilization, they are required for pollen tube attraction [21-26] and proper discharge of pollen tube contents [27-31]. In contrast to the other cell types of the female gametophyte, no clear function has been found for the antipodal cells thus far.

In Arabidopsis and most other angiosperm species, the development of the female gametophyte follows a monosporic, Polygonum-type developmental pattern, in which a single functioning megaspore undergoes three rounds 
of mitosis without cytokinesis, eventually producing a seven-celled structure with the egg cell and the two synergid cells at one pole (micropylar pole), three antipodal cells at the opposite pole (chalazal pole), and a large central cell in the center $[1,2,32]$. As in many other developmental processes [33], cell differentiation in the female gametophyte is likely under the control of gene-regulatory networks that consist of transcription factors and their downstream targets. Therefore, identification of transcription-factor genes expressed in the female gametophyte is an important step towards understanding female gametophyte development.

Much of our knowledge about female gametophyte development has been obtained through the analysis of over 100 female gametophyte mutants $[1,2,7,9,15,20,34$ 44]. However, only four of these mutants have been clearly shown to be affected in transcription-factor genes: agl80 and agl61 mutants are defective in central cell specification and development [7-9], myb98 mutants show defects in synergid cell development and function $[22,25,26]$, and agl23 mutants are defective in megagametogenesis [43]. Transcription-factor genes involved in the specific development of the egg cell or the antipodal cells have not been identified.

Expression-based analyses have also been used to identify many genes expressed in the female gametophyte. For example, cDNA libraries from isolated egg cell, central cell, synergid cells, or whole embryo sacs, have led to the identification of hundreds of female gametophyteexpressed genes in maize, wheat, tobacco, and Torenia fournieri $[23,24,45-53]$. However, few transcription-factor genes have been reported in these studies. Differential-expression screens using Arabidopsis mutants including sporocyteless (spl), determinate infertile 1 (dif1), and coatlique (coa) that lack female gametophytes have been utilized more recently to identify genes that are expressed in the female gametophyte [54-57]. These mutants are defective either in the initiation of meiosis $(s p l)$, progression through meiosis (dif1), or the initiation of megagametogenesis ( $\mathrm{coa}$ ) and therefore do not produce any female gametophytes in an otherwise normallooking ovule [54,58-60]. In these screens, mRNA profiles from wild-type and mutant ovules or pistils were compared, and genes with reduced mRNA levels (down regulated) in the mutant as compared to wild type would include those that are expressed in the female gametophyte. These microarray-based screens have identified 225 down-regulated genes in $s p l$ ovules [57], 71 and 382 down-regulated genes in dif1 ovules [55,56], and 421 down-regulated genes in coa pistils [54]. Despite the large number of genes identified in these screens, only two transcription-factor genes, MYB98 [22,56] and AT5G50915 [54], have been confirmed to be expressed in the female gametophyte. It is likely that standard microarray techniques are not sufficiently sensitive for the detection of low-prevalence mRNAs typical of most transcription-factor genes [61,62].

Here we report the identification of a large number of transcription-factor genes expressed in the Arabidopsis female gametophyte. Using quantitative reverse-transcriptase PCR (qRT-PCR), we carried out a differential expression screen of 1,482 transcription-factor genes and identified 26 genes down-regulated in dif1 mutant ovaries lacking female gametophytes. Localization of transcriptional activities within the female gametophyte was confirmed for 17 transcription-factor genes using promoter:GFP fusions. Of these, ten genes are predominantly expressed in a single cell type of the female gametophyte: the egg cell, the central cell, or the antipodal cells. The remaining seven genes are expressed in two or more cell types. We also show that 12 transcription-factor genes are transcribed in the embryo and/or the endosperm of early developing seeds. The majority of these transcription-factor genes have not been previously implicated in female gametophyte development or function. Therefore, our results provide a valuable starting point for elucidating the gene-regulatory networks governing differentiation during female gametophyte development.

\section{Results}

Quantitative RT-PCR analysis of transcription-factor mRNAs in ovaries

We carried out a differential expression screen to identify transcription-factor genes expressed in the late stages of Arabidopsis female gametophyte development, during which female gametophyte cell types are established [63]. With some modifications, we employed a strategy we previously used to identify genes expressed during female gametophyte development $[9,22,56]$. In brief, we used qRT-PCR to identify mRNAs with reduced levels in dif1 ovaries, which lack female gametophytes [59,60,64], relative to male sterile1 (ms1) ovaries, which contain wildtype female gametophytes [65-67]. The qRT-PCR reactions were performed with RNA samples obtained from dif1 and $m s 1$ ovaries harvested from flowers at developmental stages $12 \mathrm{C}$ to 14 [68], which, in wild type, contained female gametophytes at developmental stages FG5 to FG7 [63]. We normalized the raw threshold cycle values $\left(\mathrm{C}_{\mathrm{T}}\right)$ for each ms1 or dif1 reaction against $\mathrm{C}_{\mathrm{T}}$ values obtained for ACTIN2 (ACT2) mRNA (expressed as $\mathrm{C}_{\mathrm{T}, m s 1}$ and $\mathrm{C}_{\mathrm{T} \text {, difl }}$ values). We quantified the relative changes in mRNA levels between $m s 1$ and difl ovaries by determining the differences between the normalized $\mathrm{C}_{\mathrm{T}, m s l}$ and $\mathrm{C}_{\mathrm{T}}$, dif 1 values (expressed as $\Delta \Delta \mathrm{C}_{\mathrm{T}}$ ).

We carried out an initial qRT-PCR screen (referred to as the primary screen) of 1,482 transcription-factor genes (Additional file 1). To compare levels of transcription-factor mRNAs in ms1 and dif1 ovaries, the normalized single or the averaged $C_{T}$ values for each tested 
transcription-factor mRNA from the $m s 1$ and dif1 RNA sources were plotted against each other (Additional file 2 ). The data indicated that the mRNA levels of most transcription-factor genes were not affected in the ovaries by the absence of the female gametophyte [Pearson correlation $(r) \sim 0.981]$. We considered mRNAs with a $\Delta \Delta \mathrm{C}_{\mathrm{T}}$ value above 1.5 or below -1.5 to be differentially elevated in $m s 1$ or dif1 ovaries, respectively (outside the dashed lines; Additional file 2). By this criterion, 69 mRNAs were elevated in $m s 1$ as compared to dif1 $\left(\Delta \Delta C_{\mathrm{T}}\right.$ above 1.5; Additional file 2) and 58 mRNAs showed an elevated level in dif1 $\left(\Delta \Delta \mathrm{C}_{\mathrm{T}}\right.$ below -1.5; Additional file 2). The latter group likely represents genes whose activity within the ovaries is increased due to the absence of the female gametophyte in the dif1 mutant plants and was not studied further. Because the former group of transcriptionfactor mRNAs represents genes that are likely expressed in the female gametophyte, we selected them for further analysis.

The 69 transcription-factor mRNAs with $\Delta \Delta C_{T}$ values above 1.5 in the primary screen were analyzed under more stringent qRT-PCR conditions. For this, we performed three additional sets of qRT-PCR reactions (referred to as the secondary screen) using independently isolated ovary RNAs (Additional file 3). A high level of reproducibility was observed among the three biological replicates from both the $m s 1(r \sim 0.948-0.980)$ and dif1 $(r$ $\sim$ 0.916-0.941) genotypes. We applied an arbitrary threshold $\left(\Delta \Delta \mathrm{C}_{\mathrm{T}}>1.0, P<0.1\right.$, paired Student's $t$-test) to define genes that display higher levels of mRNA in $m s 1$ versus dif1 ovaries. As shown in Additional file 3, of the 69 genes tested, 26 genes were confirmed to be downregulated in dif1 ovaries.

\section{Analysis of transcription-factor gene promoter activities in the female gametophyte}

To confirm that the transcription-factor genes identified from the qRT-PCR screens are transcriptionally active in the female gametophyte and to determine their patterns of expression, we generated transgenic Arabidopsis plants carrying promoter:GFP fusion constructs for 15 of the 26 transcription-factor genes with $\Delta \Delta C_{\mathrm{T}}$ values above the statistical threshold of the secondary qRT-PCR screen (highlighted in Additional files 1 and 3; summarized in Additional file 4). In addition, we also tested 9 genes with $\Delta \Delta \mathrm{C}_{\mathrm{T}}$ values below the threshold to evaluate the stringency of the secondary screen (highlighted in Additional files 1 and 3). As discussed below, we detected promoter:GFP activity for 14 genes from the former group and three genes from the latter group indicating that our secondary qRT-PCR screen represented a relatively robust assay for identifying female gametophyteexpressed genes.
Initially, we generated transgenic plants carrying promoter constructs for six transcription-factor genes using untargeted, cytosolic GFP (cGFP) as a reporter (Table 1, Additional file 5). The promoter:cGFP expression patterns were primarily analyzed in the mature female gametophyte. As shown in Figures 1 and 2, all six genes showed patterns of promoter activity in one or more cells of the developing or mature female gametophyte. The activity of the $A T 2 G 22750 / b H L H 18$ promoter was not detected in mature female gametophytes, but weak GFP activity was detected in the antipodal cells at an earlier stage of development (FG5; Figure 1A). In the mature female gametophyte, GFP activity driven by the AT5G27880 promoter was detected exclusively in the central cell (Figure 2A). The other four promoter constructs showed more complex patterns of activity with GFP expression detectable in two (AT1G49770/ZOU/ RGE1/bHLH95; Figure 1B) and three (AT5G11050/ MYB64, AT1G75250/RL6, and AT5G01860; Figures 1C, $\mathrm{D}$ and 2D) cell types of the female gametophyte. These promoter-fusion expression patterns support the results from our qRT-PCR analysis that these genes are transcribed in the female gametophyte.

The cells of the female gametophyte are in close proximity especially in the micropylar pole where the egg cell is flanked by the two synergid cells and is positioned adjacent to the central cell cytoplasm [63]. Using epifluorescence microscopy, it proved difficult to unambiguously determine the cellular patterns of promoter activity for
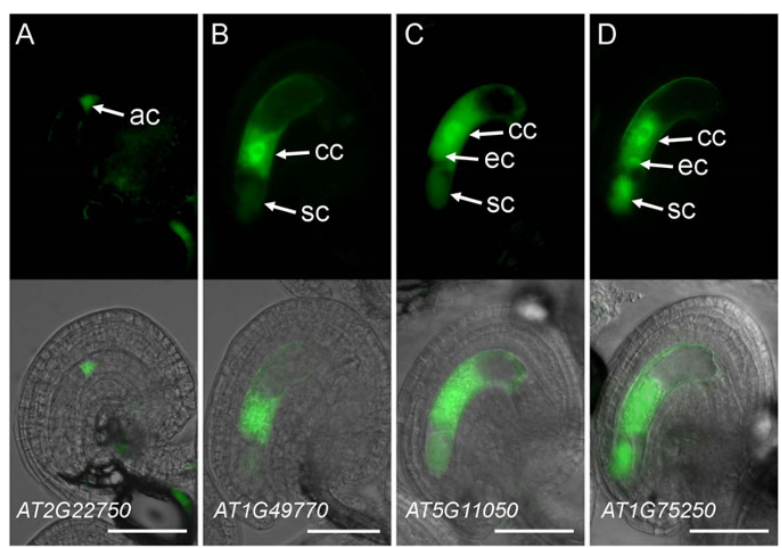

Figure 1 Expression patterns of transcription-factor promoter:cGFP fusions in the female gametophyte. (A) PAT2G22750:CGFP expression in the antipodal cells. (B) pAT1G49770:CGFP (ZOU/RGE1) expression in the central cell and the synergid cells. (C) pAT5G1 1050:CGFP (MYB64) expression in the central cell, the egg cell, and the synergid cells. (D) pAT1G75250:cGFP (RL6) expression in the central cell, the egg cell, and the synergid cells. Each panel contains an epifluorescence image (top) and an overlay (bottom) of the epifluorescence and a bright-field image of the same ovule. Images in (A) were taken at the developmental stage FG5, the rest of the images were taken at stages FG6 to FG7 [63]. ac, antipodal cells; cc, central cell; ec, egg cell; sc, synergid cell. Scale bars: $50 \mu \mathrm{m}$ 


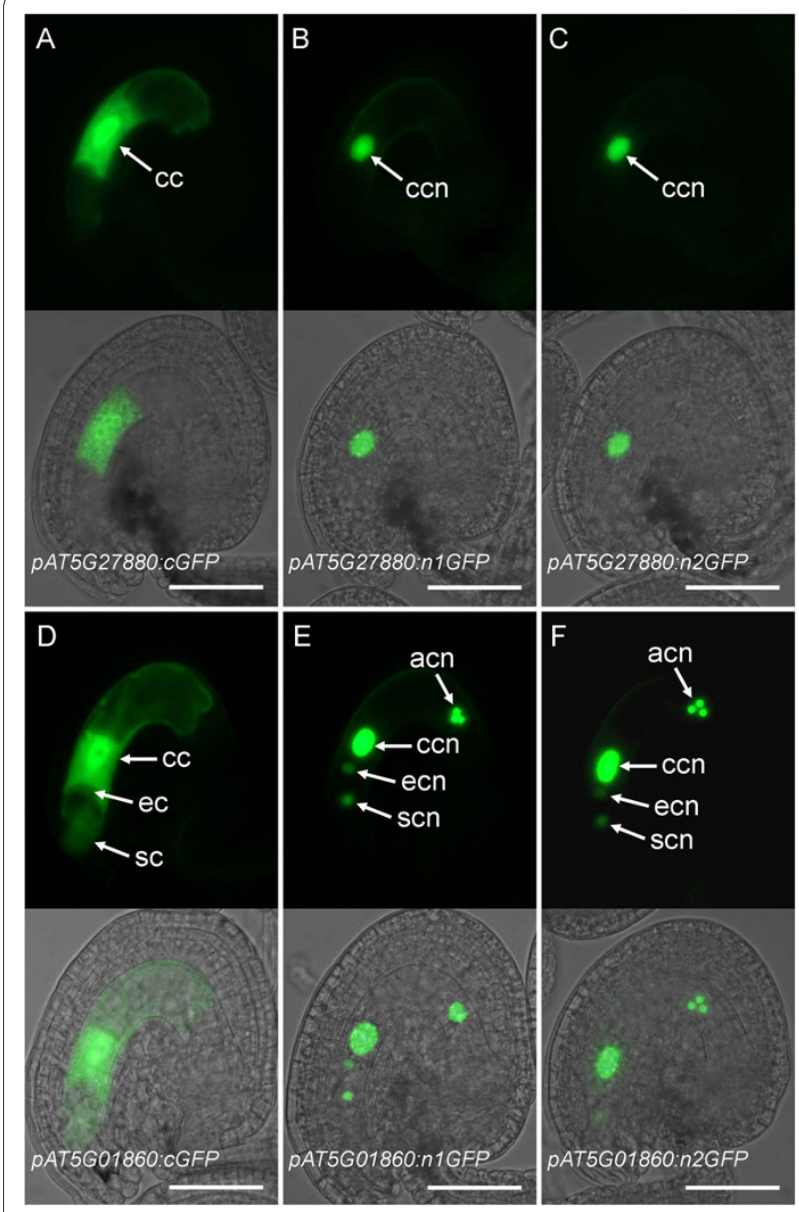

Figure 2 Comparison of cGFP, n1GFP, and n2GFP gene-reporter activities in the mature female gametophyte. Expression of AT5G27880 (A-C) and AT5G01860 (D-F) promoter constructs fused to the $\operatorname{cGFP}(\mathrm{A}, \mathrm{D}), \operatorname{n1GFP}(\mathrm{B}, \mathrm{E})$, and $n 2 G F P(\mathrm{C}, \mathrm{F})$ reporters. Each panel contains an epifluorescence image (top) and an overlay (bottom) of the epifluorescence and a bright-field image of the same ovule. acn, antipodal cell nuclei; $c c$, central cell; ccn, central cell nucleus; ec, egg cell; ecn, egg cell nucleus; sc, synergid cell; scn, synergid cell nucleus. Scale bars: $50 \mu \mathrm{m}$

genes that showed multi-cell-type expression patterns (Figures 1C, D and 2D). In addition, our qRT-PCR analysis (Additional file 3) suggests that most of the transcription-factor genes are expressed at low levels, which would produce weak GFP signals in promoter:GFP analyses. Therefore, we generated a nuclear-localized version of GFP by fusing the coding region of an Arabidopsis histone H2B gene (HTB2, AT5G22880) to the N-terminus of a single copy of GFP (n1GFP) or to two tandemly fused copies of GFP (n2GFP) in order to increase the resolution and sensitivity of our promoter:GFP analysis.

To test the utility of the nuclear-localized GFP constructs during female gametophyte development, we generated promoter constructs for genes $A T 5 G 27880$ and $A T 5 G 01860$ each fused to the $n 1 G F P$ and $n 2 G F P$ reporter genes, and compared their expression patterns in the mature female gametophyte to those obtained with the
cGFP reporter (Figure 2). Activities of both n1GFP and n2GFP driven by the $A T 5 G 27880$ promoter were localized in the central cell nucleus ( $p A T 5$ G27880:n1GFP and pAT5G27880:n2GFP; Figure 2B, C). In rare instances, weak antipodal expression was also observed (Additional files 5 and 6). This expression pattern agreed with the pattern obtained with the cGFP construct (pAT5G27880:GFP; Figure 2A). For the pAT5G01860:n1GFP and n2GFP fusions, strong GFP activity was detected in the central cell and antipodal cell nuclei, and weaker activity was detected in the egg cell and synergid cell nuclei (Figure 2E, F). The expression patterns obtained for the $n 1 G F P / n 2 G F P$ constructs were similar to that of the $c G F P$ construct except that the cGFP antipodal signals were generally weaker and only observed in rare instances (Figure 2D-F, Additional file 6). We did not detect any adverse effects of n1GFP or $n 2 G F P$ expression on female gametophyte development or function (data not shown); this observation is in agreement with previous reports where histone $\mathrm{H} 2 \mathrm{~B}$ fusions with yellow fluorescent protein or GFP were used in both animal and plant model systems without any detrimental effects on viability or development [69,70]. Moreover, we did not find any qualitative differences in the patterns of expression for $n 1 G F P$ versus $n 2 G F P$ constructs for the same promoter sequences (Figure 2B, C, E, F). These results demonstrate that the use of n1GFP/n2GFP reporters improved the sensitivity and spatial resolution of promoter:GFP analysis for studying gene expression patterns during female gametophyte development.

We constructed promoter fusions for 18 additional genes using n1GFP (15 genes) or n2GFP (3 genes) reporter constructs (Additional file 5). Eleven promoter fusions showed diverse patterns of expression in the mature female gametophyte (Table 1, Figure 3, Additional file 5), while the remaining seven genes did not show any reproducible level of GFP activity in mature female gametophytes (Additional file 5). However, all of the latter genes showed specific expression in the seed or in the sporophytic tissues of the ovary (Additional files 5 and 7) indicating that the constructs were functional. The promoter:n1/n2GFP constructs representing 13 genes (including the two described above) exhibited consistent patterns of GFP activity in the majority of primary transgenic (T1) lines (Figures 2 and 3, Additional file 5). As shown in Figures 2 and 3, expression in one, two, or all four cell types of the female gametophyte was detected using the $n 1 / n 2 G F P$ constructs. Single-cell-type expression in the central cell, egg cell and antipodal cells was detected for nine genes including AT5G50490 (Figure 3A), AT5G45980/WOX8 (Figure 3B), and AT5G56200 (Figure $3 \mathrm{C}$ ), respectively. Three promoter-fusion constructs showed expression in two cell types (usually one cell type with a higher level of expression): synergid-egg cells (AT1G60280/NAC23 and AT2G33710; Figure 3D, E) 
Table 1: Summary of qRT-PCR and promoter-fusion analyses to identify transcription-factor genes expressed in the female gametophyte.

\begin{tabular}{|c|c|c|c|c|c|c|c|}
\hline \multirow[b]{2}{*}{ AGI 1} & \multirow[b]{2}{*}{ Gene family² } & \multirow[b]{2}{*}{ Gene name ${ }^{3}$} & \multirow{2}{*}{$\begin{array}{l}\text { Primary } \\
\text { qRT screen } \\
\text { Average } \\
\Delta \Delta C_{T}\end{array}$} & \multicolumn{2}{|c|}{ Secondary qRT screen } & \multicolumn{2}{|c|}{$\begin{array}{c}\text { promoter:GFP } \\
\text { expression }\end{array}$} \\
\hline & & & & $\begin{array}{l}\text { Average } \\
\Delta \Delta C_{T}\end{array}$ & $P$ (t-test) & Ovule & Seed \\
\hline AT5G27880 & $\mathrm{C} 2 \mathrm{H} 2$ & & 6.20 & 6.63 & 0.001 & $\mathrm{C}$ & EN \\
\hline AT1G60280 & NAC & NAC23 & 4.40 & 4.29 & 0.003 & $\mathrm{~S},(\mathrm{E})$ & ne \\
\hline AT5G54070 & HSF & HSFA9 & 4.46 & 4.25 & 0.002 & & \\
\hline AT5G11050 & MYB & MYB64 & 6.24 & 4.18 & 0.001 & $\mathrm{C},(\mathrm{E}),(\mathrm{S})$ & EN \\
\hline AT2G40220 & AP2-EREBP & $A B I 4$ & 3.77 & 3.93 & 0.042 & $\mathrm{E}$ & EM \\
\hline AT2G24840 & MADS & AGL61 & 7.73 & 3.90 & 0.002 & & \\
\hline AT5G41090 & NAC & NAC95 & 4.88 & 3.81 & 0.002 & A & ne \\
\hline AT1G55600 & WRKY & MINI3/WRKY10 & 1.89 & 3.75 & 0.006 & ne & $\mathrm{EN}^{4}$ \\
\hline AT1G66390 & MYB & MYB90 & 1.77 & 3.68 & 0.071 & & \\
\hline AT5G61890 & AP2-EREBP & & 1.84 & 3.07 & 0.014 & & \\
\hline AT1G21970 & ССАAT-HAP3 & LEC1 & 4.26 & 3.03 & 0.063 & & \\
\hline AT5G01860 & $\mathrm{C} 2 \mathrm{H} 2$ & & 3.60 & 2.88 & 0.002 & $A, C,(E),(S)$ & (EN) \\
\hline AT4G00540 & MYB & MYB3R2 & 1.81 & 2.88 & 0.019 & & \\
\hline AT1G01530 & MADS & AGL28 & 3.40 & 2.84 & 0.013 & & \\
\hline AT5G56200 & $\mathrm{C} 2 \mathrm{H} 2$ & & 5.18 & 2.62 & 0.014 & A & $\mathrm{EN}^{4}$ \\
\hline AT1G35520 & ARF & ARF15 & 1.59 & 2.55 & 0.012 & A & ne \\
\hline AT1G67030 & $\mathrm{C} 2 \mathrm{H} 2$ & ZFP6 & 3.73 & 2.43 & 0.029 & A & ne \\
\hline AT5G45980 & Homeobox & WOX8 & 4.51 & 2.30 & 0.006 & $E$ & EM \\
\hline AT1G56650 & MYB & MYB75 & 1.89 & 2.26 & 0.081 & & \\
\hline AT5G58850 & MYB & MYB119 & 7.77 & 2.23 & 0.017 & & \\
\hline AT4G38070 & bHLH & & 2.13 & 2.22 & 0.020 & & \\
\hline AT1G75250 & MYB-related & RL6 & 3.02 & 1.71 & 0.011 & $C, E, S$ & EN \\
\hline AT2G33710 & AP2-EREBP & & 1.85 & 1.61 & 0.002 & $\mathrm{E},(\mathrm{S})$ & $\mathrm{EM}, \mathrm{EN}$ \\
\hline AT1G49770 & bHLH & ZOU/RGE1/bHLH95 & 2.09 & 1.61 & 0.063 & $C,(S)$ & EN \\
\hline AT3G01030 & $\mathrm{C} 2 \mathrm{H} 2$ & & 3.81 & 1.43 & 0.010 & $S,(C)$ & ne \\
\hline AT1G04370 & AP2-EREBP & ERF14 & 3.24 & 1.11 & 0.096 & & \\
\hline AT2G22750 & bHLH & & 2.46 & 0.80 & nd & $(A)^{5}$ & ne \\
\hline AT5G01380 & Trihelix & & 1.57 & 0.06 & nd & $A$ & ne \\
\hline AT5G50490 & CCAAT-HAP5 & & 2.11 & -0.27 & nd & C & EN \\
\hline
\end{tabular}

The genes are ranked in descending order based on the average $\Delta \Delta \mathrm{C}_{\mathrm{T}}$ value in the secondary qRT-PCR screen. Average $\Delta \Delta \mathrm{C}_{\mathrm{T}}$ values and $P$ values (Student's $t$-test) were calculated as described in Methods. GFP activity in female gametophytes was analyzed at one day after emasculation (corresponding to the mature stage of female gametophyte development, FG7 [63]) and in early-developing seeds at flower stage 16 (corresponding to endosperm stages $\mathrm{V}$ to $\mathrm{VI}$ and embryo stages from elongated zygote to two-cell embryo-proper [68,69]). A, antipodal cells; C, central cell; E, egg cell; EM, embryo; EN, endosperm; ne, no consistent expression; nd, not determined; S, synergid cells; (), weak expression.

${ }^{1}$ Arabidopsis Genome Initiative number.

2 Based on the classification of Arabidopsis transcription-factor genes provided by AGRIS http://arabidopsis.med.ohio-state.edu/AtTFDB and DATF http://datf.cbi.pku.edu.cn.

${ }^{3}$ Based on gene annotation provided by TAIR http://www.arabidopsis.org.

${ }^{4} \mathrm{GFP}$ activity was more intense in the micropylar endosperm compared to the chalazal and peripheral endosperm.

${ }^{5} \mathrm{GFP}$ activity was not detected at FG7 but was detected at FG5. 

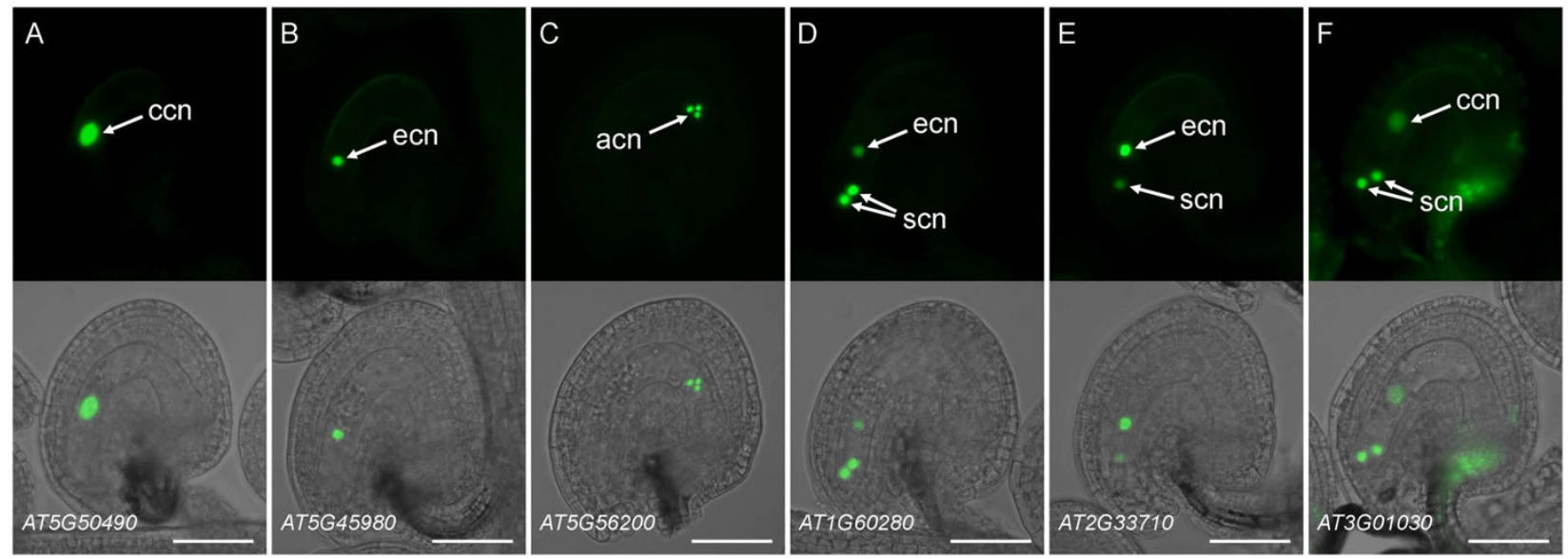

Figure 3 Expression patterns of transcription-factor promoter:n1GFP/n2GFP fusions in the mature female gametophyte. (A)

pAT5G50490:n1GFP expression in the central cell. (B) pAT5G45980:n1GFP (WOX8) expression in the egg cell. (C) pAT5G56200:n1GFP expression in the antipodal cells. (D) pAT1G60280:n1GFP (NAC23) expression primarily in the synergid cells with weaker activity in the egg cell. (E) pAT2G33710:n1GFP expression primarily in the egg cell with weaker activity in the synergid cell. (F) pAT3G01030:n2GFP expression primarily in the synergid cells with weaker activity in the central cell and the sporophytic cells of the integument and funiculus. Each panel contains an epifluorescence image (top) and an overlay (bottom) of the epifluorescence and a bright-field image of the same ovule. acn, antipodal cell nuclei; ccn, central cell nucleus; ecn, egg cell nucleus; scn, synergid cell nuclei. Scale bars: $50 \mu \mathrm{m}$

and synergid-central cells (AT3G01030; Figure 3F). Finally, expression of the AT5G01860 promoter-fusion was detected in all four cell types of the female gametophyte (Figure 2E, F). Some of the constructs showed a secondary set of expression patterns in a minority of T1 lines (Additional files 5 and 6); these patterns may be attributable to the sensitivity of the $n 1 / n 2 G F P$ reporter constructs which potentially report low levels of endogenous gene transcription not detected using previous approaches. For all reporter constructs, n1/n2GFP localization was nuclear (Figures 2 and 3, Additional file 6) except for AT5G41090/NAC95 where both nuclear and cytosolic localization patterns were observed (Additional file 6). Cytosolic localization may have resulted from an excessive amount of n2GFP fusion protein produced by a highly active promoter as the $\mathrm{C}_{\mathrm{T}}$ value for NAC95 in $m s 1$ ovaries $(26.32 \pm 0.27$, mean \pm s.d.) was the lowest (suggesting high mRNA prevalence) among the 20 transcription-factor genes analyzed using $n 1 / n 2 G F P$ promoterfusion constructs (Additional file 3). Taken together, these expression patterns demonstrate that we have identified 17 transcription-factor genes that are transcribed during late stages of female gametophyte development in Arabidopsis (Table 1, Additional file 5).

\section{Patterns of transcription-factor gene promoter activities during megagametogenesis and early seed development} Megagametogenesis and early endosperm development in Arabidopsis are characterized by a series of nuclear divisions followed by cellularization $[1,2,71]$. We first examined the expression patterns of our reporter constructs at developmental stages FG4 to FG5 of megagametogenesis before the mature, cellularized stage of female gametophyte development. Of the 19 genes tested, we did not detect a high level of promoter activity at these stages for most of the genes tested (data not shown) except for AT5G01860. As shown in Figure 4, the promoter activity for $A T 5 G 01860$ was observed in all nuclei from developmental stages FG1 to FG5 [63] with equal signal intensity. After the fusion of polar nuclei, the level of GFP activity increased in the central cell and the antipodal cells as compared to the egg cell and the synergid cells (Figure 4E). In this case, our data indicate that the initial transcriptional activity of AT5G01860 occurs as early as the initiation of megagametogenesis and that modulation of expression in late female gametophyte stages occurs after polar-nuclear fusion and immediately prior to fertilization.

To determine if the female gametophyte-expressed transcription-factor genes are also expressed during endosperm and/or embryo development, we analyzed all of our reporter constructs at flower stage 16 [68], which corresponds to stages V (16-nucleate stage) to VI ( 30nucleate stage) of endosperm development and in the elongated zygote to two-cell embryo-proper stage of embryogenesis $[68,69]$. We observed consistent embryo and/or endosperm expression for 12 promoter-fusion constructs (Additional file 5). The majority of the reporter constructs (7 genes; Additional file 5) showed a relatively uniform pattern of expression in the endosperm when assayed using cGFP ( $\mathrm{ZOU}$; Figure 5A) or nuclearlocalized GFP (AT5G50490; Figure 5B) while reporter constructs for genes AT1G55600/MINI3 and AT5G56200 showed preferential GFP activity in the micropylar endosperm (Figure 5C, Additional file 5). With two genes, WOX8 and AT2G40220/ABI4, expression was observed 


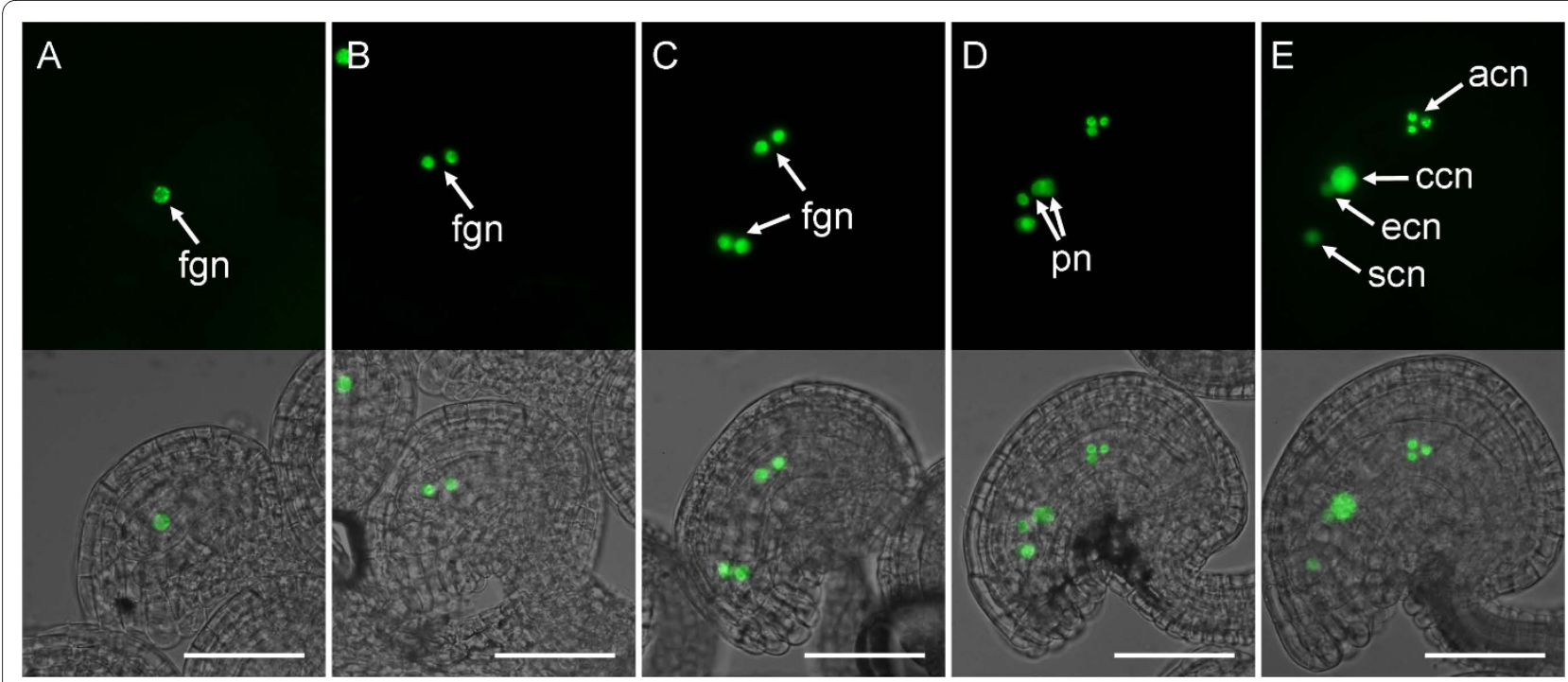

Figure 4 Expression of pAT5G01860:n1GFP during megagametogenesis. Expression at developmental stage FG1 (A), FG2 (B), FG4 (C), FG5 (D), and FG6 (E) of the developing female gametophyte [63]. Each panel contains an epifluorescence image (top) and an overlay (bottom) of the epifluorescence and a bright-field image of the same ovule. acn, antipodal cell nuclei; ccn, central cell nucleus; ecn, egg cell nucleus; fgn, female gametophyte nuclei; pn, polar nuclei; scn, synergid cell nucleus. Scale bars: $50 \mu \mathrm{m}$.

in early embryos with very low or no detectable activity elsewhere in early seeds (Figure 5D, Additional file 5). Finally, the AT2G33710 promoter-fusion construct showed expression in both the embryo and endosperm (Figure 5E). Of the 17 transcription-factor genes expressed in the female gametophyte, 10 showed consis-
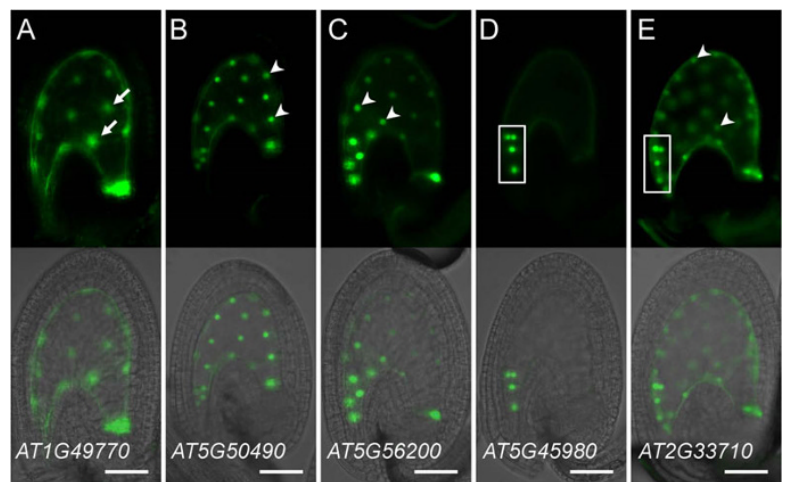

Figure 5 Expression patterns of transcription-factor promoter:cGFP and promoter:n 1GFP fusions during early seed development.(A) pAT1G49770:CGFP (ZOU/RGE1) activity in endosperm nuclear cytoplasmic domains (NCDs) [104]. (B) pAT5G50490:n1GFP activity in endosperm nuclei. (C) pAT5G56200:n 1GFP activity primarily in micropylar endosperm nuclei. (D) pAT5G45980:n1GFP (WOX8) expression in pro-embryo nuclei. (E) pAT2G33710:n1GFP activity in both endosperm and pro-embryo nuclei. Each panel contains an epifluorescence image (top) and an overlay (bottom) of the epifluorescence and a bright-field image of the same seed. The micropylar region of the seed is oriented towards the left side of the panel. Arrows point to endosperm NCDs, and arrowheads point to endosperm nuclei. Boxed areas indicate the micropylar location of the embryos. Scale bars: $50 \mu \mathrm{m}$. tent expression in the seed (Table 1). Together, our analysis indicates that a significant portion of the female gametophyte-expressed transcription-factor genes are also transcribed during early seed development.

\section{Discussion}

Utility of our qRT-PCR-based differential-expression screen

We performed a two-step qRT-PCR screen to identify transcription-factor genes with reduced mRNA levels in dif 1 ovaries compared to $m s 1$ ovaries. In the primary screen, 69 genes were identified as dif1 down-regulated (reduced levels in dif1 as compared to ms1) while 58 genes were identified as dif1 up-regulated (Additional files 1 and 2). Although dif1 and ms1 ovules are apparently indistinguishable in terms of integument morphology [56], the other sporophytic organs/tissues of the dif1 ovaries may show altered gene expression patterns due to the absence of the female gametophyte. Therefore, in addition to the female gametophyte-expressed genes that are of primary interest to this study, the dif1-down-regulated genes might include sporophyte-expressed genes that are induced by the female gametophyte. While this is an unlikely possibility for all of the transcription-factor genes assayed, the promoter-fusion assays were designed, in part, to address this issue (Additional file 4). On the other hand, the dif1-up-regulated genes may include genes that are normally repressed in the ovary by the female gametophyte. Although sporophyte-expressed genes of this type are not the focus of this study, these transcription-factor genes, once confirmed, could represent important developmental regulators mediating the 
communication between the female gametophyte and the surrounding sporophytic organs and tissues.

Of the 69 dif1-down-regulated genes, 26 genes were further validated in an additional series of qRT-PCR assays (secondary screen) under more stringent PCR conditions (Additional file 3). We and others previously used microarray-based differential expression screens to identify a total of 63 unique transcription-factor genes with reduced mRNA levels in the ovules or pistils of $s p l$, coa or dif1 mutant plants (Additional file 8) [54,56,57]. An additional screen comparing dif 1 ovules to fertilized wildtype seeds led to the identification of another five transcription-factor genes (Additional file 8) [55]. However, there is no significant overlap in the detection of genes among the published microarray-based screens and the present study (Additional file 8). This discrepancy may be attributed, in part, to differences in sampling of the material (e.g., ovules versus ovaries), the developmental staging of the material (e.g., mature versus developing female gametophytes), or any effect the mutations might have had on the sporophytic tissues of the sampled material (i.e., ovule, ovary, seeds or pistil). A direct comparison of the approaches awaits further confirmation of the expression of the candidate genes.

Of the 24 novel genes identified in this study (Additional files 3 and 8) [54-57], 13 genes were analyzed using promoter fusions with 12 showing transcriptional activity in the female gametophyte (Table 1). Such a high proportion of validated genes suggests that the majority of the original 24 genes uniquely identified in our qRT-PCR screen are likely transcribed in the female gametophyte. The failure to identify these 24 genes in the previous studies could be due to low mRNA levels that are below the detection limits of the microarray assays. This conclusion is supported by our observation that the majority of these 24 genes showed relatively high $\mathrm{C}_{\mathrm{T}}$ values (low mRNA levels) in $m s 1$ ovaries: 22 genes displayed normalized $\mathrm{C}_{\mathrm{T}}$ values above 28 (Additional file 3 ), while the two genes (MYB64 and NAC95) identified in the previous microarray studies displayed $C_{T}$ values between 26 and 28 (Additional file 3). Taken together, our results demonstrate that our qRT-PCR-based differential expression screen is sensitive enough to detect low-prevalence mRNAs of transcription-factor genes in the female gametophyte.

\section{Identification of transcription-factor genes expressed in the female gametophyte}

We tested 15 of the 26 transcription-factor genes exhibiting reduced mRNA levels in dif1 ovaries in our qRT-PCRbased screen (Additional file 3) using promoter:GFP fusions and confirmed that 14 are transcribed within the female gametophyte (Table 1, Figures 1, 2, and 3). The single non-expressing-promoter construct (MINI3) may not have contained all the cis-regulatory sequences required for proper expression in the female gametophyte. Of the 11 genes that were not tested using promoter fusions, one (AGL61) had been isolated using a similar differential screen and its promoter activity in the female gametophyte had been described previously $[7,9]$. Therefore, it is likely that most of the remaining untested genes are also expressed in the female gametophyte. In addition, we tested nine genes below the statistical threshold of the secondary screen using promoter fusions (Additional file 5). Three exhibited female gametophyte expression (Table 1, Figures 1A and 3A), suggesting that additional female gametophyte-expressed genes can be identified in this group. Of a total of 17 genes exhibiting female gametophyte expression, 10 were predominantly transcribed in a single cell type: the egg cell (2 genes), the central cell ( 2 genes), or the antipodal cells ( 6 genes; Table 1 ). The remaining seven genes were transcribed in multiple cell types within the female gametophyte (Table 1).

Our analyses uncovered novel patterns of transcription-factor gene activity in the female gametophyte and during early seed development. We also confirmed some previously described patterns of gene activity, supporting our general approach to identifying low-prevalence transcription-factor mRNAs in the female gametophyte. Six transcription-factor genes displayed strong promoter:GFP activity exclusively (AT5G50490 and $A T 5 G 27880)$ or predominantly (ZOU/RGE1, RL6, AT5G01860, and MYB64) in the central cell and also in the endosperm (Table 1; Figures 1B-D, 2, 3A and 5A, B). Among these, ZOU/RGE1/bHLH95 encodes a bHLH transcription factor that has been proposed to regulate endosperm adhesion and breakdown which, in turn, is required for the proper epidermal development of the embryo [72,73]. Our promoter-fusion analysis suggests that $Z O U / R G E 1$ is transcribed in the central cell, the synergid cells, and the endosperm (Table 1; Figures $1 \mathrm{~B}$ and $5 \mathrm{~A})$. This differs from the previous reports where expression of ZOU/RGE1 was only observed in the endosperm $[72,73]$. The discrepancy may be due to different promoter lengths and the type of reporter genes used in the studies. RL6 encodes a MYB-related transcription factor expressed in the micropylar endosperm [74]. The expression patterns of the remaining four "central cellendosperm" genes (AT5G01860, AT5G27880, AT5 G50490, and MYB64) have not been described previously. However, supporting our promoter-reporter data, an analysis of the publicly available microarray data using Genevestigator indicates mRNA accumulation for AT5G01860 and MYB64 in the endosperm https:// www.genevestigator.com.

In contrast to the genes with transcriptional activity in both the central cell and the endosperm, we detected endosperm expression for three genes that showed no expression in the central cell (Table 1, Figure 5C, E). The transcriptional activity of $A T 5 G 56200$ or $A T 2 G 33710$ has 
not been described previously. However, available microarray data indicate mRNA accumulation for both genes in laser-captured endosperm samples https:// www.genevestigator.com[75]. MINI3 encodes a WRKY transcription factor that has been shown to regulate endosperm growth and cellularization [76]. We detected MINI3 promoter activity in the endosperm but not in the female gametophyte (Table 1) in agreement with a previous report [76].

Three transcription-factor genes exhibited strong promoter:GFP activity exclusively ( $A B I 4$ and WOX8) or predominantly (AT2G33710) in the egg cell (Table 1, Figure $3 B, E)$. All three were expressed in the embryo after fertilization (Table 1, Figure 5D, E). $A B I 4$ is primarily expressed in the embryo during seed maturation and encodes an AP2-EREBP transcription factor required for $\mathrm{ABA}$ and sugar signaling during seed development and germination [77-79]. Transcription of ABI4 in the egg cell has not been reported previously. WOX8 encodes a homeobox transcription factor that is involved in regulating early embryo development [80-82]. Using in situ hybridization, WOX 8 mRNA has been localized to the egg cell and the basal-cell lineage of the developing embryo [80]. However, our WOX8 promoter fusion showed expression in both the apical and basal cell lineages of the embryo (Figure 5D). This construct may not contain all of the cis-regulatory elements required for proper transcription of the reporter gene including elements to suppress transcription in the apical cell lineage. Alternatively, WOX8 mRNA may be degraded preferentially in the apical-cell lineage or be redistributed to the basal cell upon the first zygotic division as has been suggested previously [80]. We also detected reduced mRNA levels in dif1 ovaries for AT5G54070/HSFA9 and AT1G21970/LEC1 (Table 1) previously shown to be required for embryogenesis $[83,84]$. Transcriptional patterns of these two genes in the female gametophyte remain to be determined.

We found that among the 17 transcription-factor genes active in the female gametophyte, nine genes are highly transcribed in the synergid or the antipodal cells (Table 1 ), the two cell types of the female gametophyte that do not give rise to any cells or tissues of the developing seed. The promoter fusions for NAC23 and AT3G01030 were expressed predominantly in the synergid cells with weak expression in the egg cell or the central cell (Table 1). This is essentially similar to the expression pattern observed for MYB98 [22,85]. We found that RL6 is also expressed in the synergid cells, the central cell, and the egg cell (Table 1). MYB98 has been shown to control at least a portion of the gene regulatory network required for proper synergid cell differentiation [26]. Therefore, NAC23, AT3G01030 and RL6 may constitute additional components of the same or a larger network controlling synergid cell differentiation and function. At the opposite, chalazal pole, we have identified six transcriptionfactor genes that are highly expressed in the antipodal cells (Table 1, Figures 2E, F and 3C). The function of these genes is not known. Among them, AT1G35520/ ARF15 might play a role in the transcriptional regulatory networks responding to the plant hormone auxin, which has been shown recently to regulate cell fate specification in the female gametophyte [86].

Among the 26 transcription-factor genes we have described here (Additional file 3), only one gene (AGL61) previously had been shown to be functionally required in the female gametophyte $[7,9]$. It is possible that gene redundancies or functional compensations may have precluded isolation of these transcription-factor genes in genetic screens for female-gametophyte mutants. This hypothesis is supported by the observation that some of the genes identified in this study are structurally similar. For example, three (AT1G67030, AT5G01860, and AT5G27880) of the five C2H2-type transcription-factor genes we identified are closely related homologues [87]. Interestingly, a number of the female gametophyteexpressed transcription-factor genes isolated in this study (see above) have been shown to be required after fertilization [72,73,76-84,88-91]. It remains to be determined whether they perform any function in the female gametophyte as individual genes, or as members of multi-gene families with complex expression programs encompassing both the gametophytic and the zygotic portions of the plant life cycle.

\section{Conclusions}

To begin to identify the gene-regulatory networks controlling angiosperm female gametophyte development, we performed a large-scale qRT-PCR-based differential expression screen of nearly all transcription-factor genes in Arabidopsis ovaries. Compared to microarray-based methods [54-57], our approach proved to be more sensitive and allowed the identification of 26 transcription factor genes, the majority of which previously had not been identified as female gametophyte-expressed genes. We further confirmed transcriptional activity of 17 genes in the female gametophyte using promoter-fusion analyses. Using a nuclear-localized GFP reporter, we have developed female gametophyte-cell-specific marker lines well suited for monitoring individual cell fates during female gametophyte development and early seed development. Transcription factors are at the center of gene regulatory networks and perform essential regulatory roles in development and cell differentiation [33]. The transcriptionfactor genes identified in this study can be used to dissect the gene regulatory networks in the female gametophyte through a combination of genetic and molecular approaches, ultimately enabling a better understanding of 
the molecular mechanisms that control female gametophyte development and function during plant reproduction.

\section{Methods}

\section{Plant material and growth conditions}

The dif1-2 and ms1-1 mutant alleles, initially isolated in the Landsberg erecta (Ler) background [60,67], were backcrossed four and seven times, respectively, to Ler. Plant transformations were performed with the Columbia-0 (Col-0) ecotype. Arabidopsis plants were grown at $22^{\circ} \mathrm{C}$ under continuous light or 16-hr light/8-hr dark photoperiod as described previously $[19,56]$.

\section{Tissue collection, RNA isolation and CDNA synthesis}

Homozygous dif 1 and $m s 1$ mutant plants were identified based on their male-sterile phenotype among the progeny from a self-fertilization of $d i f 1 /+$ and $m s 1 /+$ parents $[60,66,67,92]$. Ovaries were collected from dif1 and ms1 mutant plants by removing the stigma and style from the pistils harvested at flower stages $12 \mathrm{C}$ [63] to 13 or 14 [68]. Seven pairs of dif1 and $m s 1$ RNA samples were used in this study (Additional file 9). Each RNA sample was extracted from 100 to 150 ovaries using the RNeasy Plant Mini Kit (Qiagen, Hilden, Germany) or TRIzol ${ }^{\circ}$ Reagent (Invitrogen, Carlsbad, USA) and purified with the RNeasy MinElute Cleanup Kit (Qiagen) after a treatment with TURBO DNase (Ambion, Austin, USA) to remove any genomic DNA. The purified RNAs were then reverse transcribed with Oligo-dT primers using the RETROscript Kit (Ambion) or SuperScript III Reverse Transcriptase (Invitrogen) following the manufacturer's instructions. For most samples, first-strand cDNA was further purified using the MinElute PCR Purification Kit (Qiagen) after an RNase H treatment (New England Biolabs, Beverly, USA).

\section{Primer design}

The majority of the primer-pairs $(1,356$ out of 1,482$)$ used in the primary qRT-PCR screen (Additional file 1) were described previously [93]. The rest of the primer-pairs were designed de novo, including primers for 70 additional transcription-factor genes annotated by the Arabidopsis Gene Regulatory Information Server http:// arabidopsis.med.ohio-state.edu[94,95] or the Database of Arabidopsis Transcription Factors http://datf.cbi. pku.edu.cn[96]. The same primers were used in the secondary qRT-PCR screen with the exception of 17 primerpairs, which were redesigned to ensure specific PCR amplification (Additional file 3). The primer sequences were designed based on gene structure models at the Arabidopsis Information Resource http://www.arabidopsis.org (TAIR) using LightCycler Probe Design Software 2.0 (Roche, Mannheim, Germany) and by setting the primer melting temperature at $60^{\circ} \mathrm{C}$. The amplicon sizes ranged between 68 and $261 \mathrm{bp}$. The transcription-factor genes analyzed in this study and the corresponding primer-pair sequences are listed in Additional files and. Based on analysis of melting curves (see below), 94.7\% of the primer pairs produced a single identical PCR product for each pair of ms1-dif1 qRT-PCR reactions, indicating that a significant majority of the primer pairs were gene specific under our experimental conditions (Additional file 1).

\section{Quantitative RT-PCR experimental setup and data analysis}

Quantitative RT-PCR was performed using a LightCycler 1.5 instrument in a 32-capillary format (Roche). The PCR program for the primary screen consisted of an initial denaturing step at $95^{\circ} \mathrm{C}$ for 5 min, followed by 45 cycles at $95^{\circ} \mathrm{C}$ for $15 \mathrm{~s}, 60^{\circ} \mathrm{C}$ for $15 \mathrm{~s}$, and $72^{\circ} \mathrm{C}$ for $10 \mathrm{~s}$. The cycle parameters were changed to $95^{\circ} \mathrm{C}$ for $10 \mathrm{~s}, 60^{\circ} \mathrm{C}$ for $5 \mathrm{~s}$, and $72^{\circ} \mathrm{C}$ for $10 \mathrm{~s}$ in the secondary screen in order to increase the stringency of the PCR reactions. Standard melting-curve analysis provided by the instrument manufacturer was performed after each PCR run to determine whether a single PCR product was amplified in each reaction and whether the same product was amplified from both $m s 1$ and dif 1 cDNA sources. The $\mathrm{C}_{\mathrm{T}}$ values were calculated using the standard approach provided in the LightCycler software 4.0 package (Roche).

To determine whether ACT2 is a suitable reference gene, levels of $A C T 2$ mRNA were quantified with qRTPCR in three independent pairs of $m s 1$ and dif 1 RNA samples. All experimental procedures from reverse transcription to qRT-PCR analysis were conducted side-byside using the same amount of RNA. The $\mathrm{C}_{\mathrm{T}}$ values for $A C T 2$ in $m s 1(18.39 \pm 0.29$, mean \pm s.d. $)$ and dif1 $(18.40 \pm$ 0.17 , mean \pm s.d.) RNAs did not differ significantly $(P=$ 0.93, paired Student's $t$-test), indicating that the level of ACT2 mRNA in the ovary is not affected by the absence of the female gametophyte.

Each qRT-PCR run consisted of 16 pairs (dif1 and $m s 1$ ) of $10-\mu \mathrm{l}$ reactions containing 2.5 or $5.0 \mathrm{pmol}$ of primers and an aliquot of the master mix, which was assembled by combining the dif 1 or $m s 1 \mathrm{cDNA}$ with the master mix from the LightCycler FastStart DNA Master PLUS SYBR Green I Kit according to manufacturer's instructions (Roche). The amount of cDNA used in the master mix was adjusted so that each reaction contained cDNA from 10-15 ng of total RNA. To account for the variation in template concentration between PCR runs, each run contained a pair of $m s 1$ - dif1 reactions for ACT2, which was used to normalize the $C_{T}$ values of the target genes analyzed in the same run (normalized $C_{T}$, target $=C_{T}$, target $-C_{T}$, $\left.{ }_{A C T 2}+19\right)$. The majority of the qRT-PCR runs produced $\mathrm{C}_{\mathrm{T}}$ values around 19 for $A C T 2$. The amount of cDNA template for a specific transcription-factor gene was considered negligible when the $C_{T}$ value was at or above 36 . 
Therefore, the normalized $C_{T}$ values were manually cut off at 36. Differences in mRNA levels between $m s 1$ and dif1 RNA samples were calculated using the $-\Delta \Delta C_{\mathrm{T}}$ method [97] where $\Delta \Delta \mathrm{C}_{\mathrm{T}}=$ normalized $\mathrm{C}_{\mathrm{T} \text {, dif1 }}$ - normalized $\mathrm{C}_{\mathrm{T}, m s 1}$.

We have previously shown that qRT-PCR is sensitive enough to detect reduced MYB98 mRNA level in dif1 versus wild-type pistils [22]. Therefore, a pair of $m s 1$ - dif 1 reactions for MYB98 was included in each PCR run as a positive control. All seven pairs of ms1- dif1 RNA samples used in this study exhibited significantly higher levels of MYB98 mRNA in ovaries from ms 1 as compared to dif1 mutant plants $(P<2.50 \mathrm{E}-05$, Student's $t$-test; Additional file 9).

In the primary screen, the majority of genes $(1,265$ out of 1,482$)$ were analyzed once, and the $\Delta \Delta \mathrm{C}_{\mathrm{T}}$ was calculated as described above. Additional replicates using either the same or different RNA samples were conducted for the remaining 217 genes, and an average $\Delta \Delta C_{T}$ was calculated by averaging data from technical replicates followed by averaging the resulting means for biological replicates. Calculation of the Pearson correlation coefficients and the Student's $t$-test were performed using the corresponding functions in Excel (Microsoft, Redmond, USA).

\section{Promoter-fusion constructs}

Four binary transformation vectors (pBI-GFP[S65T] [98], pBI-1GFPB, pBI-n1GFP, and pBI-n2GFP) were used in the construction of promoter fusions with reporter genes GFP, $n 1 G F P$, and $n 2 G F P$ (Additional file 10); these vectors were generated as follows. A synthetic linker containing multiple cloning sites (5'- aagcttcctgcagg ttaa cag tactcacgtgaggcctactagtgagctcggtaccctcgaggtcgactctagaggatcc-3') was cloned into the pBI-GFP[S65T] vector [98] between HindIII and BamHI sites resulting in pBI-1GFP.

The GFP coding region was amplified from pBIGFP [S65T] [98] with the forward primer (5'-caaacaacgggatccatggtgagcaagggcgag- $\left.3^{\prime}\right)$ and the reverse primer encoding an (Ala) $)_{8}$ linker (5'-aaaa aaagaagatctagcagcagcag cagcagcagcagccttgtacagctcgtccatgc-3'). The PCR product was then digested with BamHI and BglII and inserted into the BamHI (compatible with BglII) site of pBI-1GFP resulting in $\mathrm{pBI}-2 \mathrm{GFP}$.

Two DNA oligonucleotides (5'-tcgactctagaggatccggccggcctggaggtggaggtggagcta-3' and 5'-gatctagctccacctccacctc caggccggccggatcctctagag- $3^{\prime}$ ) were annealed to generate a linker with SalI/BglII $\left(5^{\prime} / 3^{\prime}\right)$ cohesive ends, which contained an $\mathrm{XbaI}$ and a BamHI site upstream of sequences encoding the peptide GlyArgPro(Gly) ${ }_{5}$ Ala. This linker was then cloned into pBI-1GFP between SalI and BamHI sites resulting in $\mathrm{pBI}-1 \mathrm{GFPB}$.

The coding region of the HTB2 gene was amplified from Col-0 genomic DNA with the forward primer HTB2F (5'-gactcgggatccatggcgaaggcagataagaaacc-3') and the reverse primer HTB2R2 encoding an (Ala) ${ }_{4}$ linker $\left(5^{\prime}-\right.$ gaaaaaaagaagatctagcagcagcagcagaactcgtaaacttcgtaaccgc$\left.3^{\prime}\right)$. Two silent mutations $\left(\mathrm{ATC}_{60}\right.$ to ATA and $\mathrm{CTT}_{101}$ to CTG) were introduced via a series of PCR reactions to remove HindIII and BglII sites from the coding region of HTB2. To do this, the coding region of HTB2 was amplified as two separate fragments using primer pairs HTB2F plus HTB2LUR2 (5'- cttgcttcaacaccttgaagatgtaTatcttgtatgtctcaacgttcttc - 3 ', the mutagenized nucleotide is uppercase), and HTB2LDF2 (5'- gaagaacgttgagacataca agatA tacatcttcaaggtgttgaagcaag $-3^{\prime}$ ) plus HTB2R2. The two fragments were then fused through an overlap-extension PCR $[99,100]$ using the primer pair HTB2F plus HTB2R2 resulting in a full-length $H T B 2$ PCR product containing the mutation $\mathrm{ATC}_{60}$ to ATA. This product was further mutagenized by repeating the steps described above with a different set of primers: HTB2F plus HTB2LUR (5'ggcttcttgttgtacctcgcCagcttcgaagactcaccagc -3 ') and HTB2LDF (5'- gctggtgagtcttcgaagctGgcgaggtacaacaag aagcc -3 ') plus HTB2R2. The resulting PCR product containing both mutations was digested with BamHI and $B g l \mathrm{II}$ and inserted into the BamHI site of pBI-1GFP and pBI-2GFP resulting in pBI-n1GFP and pBI-n2GFP, respectively.

For each transcription-factor gene analyzed, promoter regions containing between 800 and 2,700 bp of the upstream and between 9 and 39 bp of the downstream sequence to the translation start site were amplified from Col-0 genomic DNA using primers containing restriction sites or homologous recombination sites (Additional file 10). The PCR products were inserted into pBIGFP[S65T] [98], pBI-1GFPB, pBI-n1GFP, or pBI-n2GFP using conventional cloning procedures based on restriction digestion or through the use of the In-Fusion technology according to manufacturer's instructions (BD Biosciences, Heidelberg, Germany) as indicated in Additional file 10. The PCR amplifications were performed using PfuUltra (Stratagene, La Jolla, USA) or ExTaq (Takara, Otsu, Japan) DNA polymerases. All promotervector junctions were verified by sequencing.

\section{Plant transformation}

Arabidopsis plants were transformed as described previously [19,56] with Agrobacterium tumefaciens strains GV3101 pMP90 [101] or LBA4404 [102] containing the GFP binary vectors using the standard floral dip method 
[103]. The presence of the transgene in each $\mathrm{T} 1$ plant was confirmed using PCR.

\section{Analysis of gene-promoter activity}

GFP activity within the mature female gametophyte was analyzed one day after emasculation as previously described [56]. Expression patterns during early female gametophyte development were analyzed in ovules from floral stages $12 \mathrm{~B}$ to $13[63,68]$ containing female gametophytes at developmental stages FG1 to FG6 [63]. Seeds were analyzed in self-fertilized siliques at floral stage 16 [68] containing early nuclear stages of endosperm development [69]. Promoter activity within the mature female gametophyte was analyzed in T1- or T2-generation plants. Between 5 and 16 T1 lines per construct (Additional file 5) were examined to verify the expression patterns described above. Transformation of plants with promoter-less pBI-n1GFP or pBI-n2GFP vectors did not produce any detectable levels of GFP activity above background in the relevant tissues.

Image acquisition and processing were carried out as described previously $[19,56]$. In brief, the bright-field and epifluorescence images of ovules and young seeds were captured using either a MicroFire CCD camera (Optronics, Goleta, USA) or an AxioCam MRm REV2 camera (Carl Zeiss, Jena, Germany) attached to an Axiophot or an Axioplan compound epifluorescence microscope (Carl Zeiss) equipped with an enhanced GFP bandpass filter (filter set 38 HE EGFP, exciter 450-490 nm, dichroic 495 $\mathrm{nm}$, emitter 500-550 nm; Carl Zeiss). Image processing, including creation of the overlays of epifluorescence and bright-field images, was performed using Photoshop CS (Adobe Systems Inc., San Jose, USA).

\section{Additional material}

Additional file 1 Primary qRT-PCR screen of Arabidopsis transcription-factor genes. Provided information includes: AGI numbers, primer sequences, amplicon sizes, and $C_{T}$ values for 1,482 transcription-factor genes analyzed in the primary qRT-PCR screen.

Additional file $\mathbf{2}$ Summary of the primary qRT-PCR screen. (A) Comparison of mRNA levels in $\mathrm{ms} 1$ and dif1 ovaries. Average $C_{T}$ values for the $\mathrm{ms} 1$ and dif1 ovary RNAs were compared for each transcription-factor gene analyzed. Dashed lines indicate the threshold of the primary screen $\left(\Delta \Delta C_{T}>1.5\right.$ or $\left.\Delta \Delta C_{T}<-1.5\right)$. (B) Histogram illustrating the distribution of $\Delta \Delta C_{T}$ values obtained for all transcription-factor genes in the primary screen.

Additional file 3 Secondary qRT-PCR screen of selected transcriptionfactor genes. Provided information includes: AGI numbers, primer sequences, amplicon sizes, and $C_{T}$ values for 69 transcription-factor genes analyzed in the secondary qRT-PCR screen.

Additional file $\mathbf{4}$ Validation of the primary and secondary qRT-PCR screens with promoter-fusion analyses. Venn diagram illustrating a significant overlap between the genes validated using the secondary qRT-PCR screen and the promoter-fusion analyses.

Additional file $\mathbf{5}$ Summary of promoter-fusion analyses. Expression patterns of 28 promoter:GFP fusions representing 24 transcription-factor genes in the female gametophyte and during early seed development.
Additional file 6 Secondary expression patterns of transcription-fac tor promoter:CGFP/n1GFP/n2GFP fusions in the female gametophyte. Epifluorescence images (A-I) were obtained from mature female gametophytes at 1DAE. Solid arrows indicate consistent expression patterns. Open arrows indicate expression patterns observed in rare instances (see Additional File 5 for details). (A) pAT1G35520:n1GFP expression in the antipodal cells and the synergid cells. (B) pAT1G49770:CGFP expression in the central cell, the synergid cells, and the egg cell. (C) pAT1 G55600:n1GFP expression in the central cell. (D) pAT3G01030:n2GFP expression in the synergid cells, the central cell, and the egg cell. (E) pAT5G01860:CGFP expression in the central cell, the egg cell, the synergid cells, and the antipodal cells. (F)

pAT5G27880:n1GFP expression in the central cell and the antipodal cells. (G) pAT5G41090:n2GFP expression in the cytoplasm of the antipodal cells. (H) pAT5G45980:n1GFP expression in the egg cell and the synergid cells. (I) PAT5G56200:n1GFP expression in the antipodal cells, the central cell, the egg cell, and the synergid cells. ac, antipodal cells; acn, antipodal cell nuclei; cc, central cell; ccn, central cell nucleus; ec, egg cell; ecn, egg cell nucleus; sc, synergid cells; scn, synergid cell nuclei. Scale bars: $50 \mu \mathrm{m}$.

Additional file 7 Secondary expression patterns of transcription-factor promoter:n1GFP/n2GFP fusions during early seed development. Epifluorescence images (A-C) were obtained from developing seeds at flower stage 16. Arrows point to endosperm nuclei. Boxed areas indicate the micropylar location of the embryo. (A) pAT3G01030:n2GFP expression in stage III endosperm and in sporophytic cells of the integument and funiculus. (B) pAT5G01380:n1GFP expression in the zygote. (C) pAT1G60280:n1GFP expression in stage $V$ endosperm and the pro-embryo. Scale bars: $50 \mu \mathrm{m}$.

Additional file 8 Comparison of data obtained in this study with data obtained from previously reported microarray-based screens. Venn diagram illustrating the limited overlap between the transcription-factor genes identified in the five independent studies.

Additional file 9 qRT-PCR analysis of MYB98 in seven pairs of ms 1-dif1 ovary RNAs used in this study.

Additional file 10 Construction of promoter fusions for selected transcription-factor genes. Provided information includes primer sequences used for constructing promoter fusions.

\section{Authors' contributions}

GND, RY and KSS conceived the research, supervised and coordinated all research activities. DW, CZ, DJH, I-HK and JAP carried out qRT-PCR reactions. CZ and DJH generated transcription factor promoter constructs. CZ, DW and MIS generated and analyzed transgenic lines. DW, RY, KSS and GND analyzed all data and wrote the manuscript. All authors read and approved the final manuscript.

\section{Acknowledgements}

We thank Josh Steffen for providing the GFP images of MYB64 and RL6 promoter analyses. We also thank Lauren Bergstrand, Mayuko Ikehara and Batool Hosseinpour for their technical assistance in generation and analysis of the transgenic Arabidopsis lines. This work was supported by an Arabidopsis-2010 Project grant from the U.S. National Science Foundation (IOS-0520008).

\section{Author Details}

1School of Plant Sciences, University of Arizona, Tucson, Arizona 85721-0036, USA, ${ }^{2}$ Department of Biology, University of Utah, Salt Lake City, Utah 84112 0840, USA, ${ }^{3}$ Current Address: The Section of Molecular, Cell and Developmental Biology, University of Texas at Austin, Austin, Texas 78712-0159, USA, ${ }^{4}$ Current Address: Department of Biological Sciences, Towson University, Towson, Maryland 21252-0001, USA, ${ }^{5}$ Current Address: Department of Horticulture, lowa State University, Ames, lowa 50011-1100, USA and ${ }^{6}$ Current Address: Department of Biology, University of North Carolina at Chapel Hill, Chapel Hill, North Carolina 27599-3280, USA

Received: 11 December 2009 Accepted: 16 June 2010 Published: 16 June 2010

\section{References}

1. Drews $G N$, Yadegari R: Development and function of the angiosperm female gametophyte. Annu Rev Genet 2002, 36:99-124.

2. Yadegari R, Drews GN: Female gametophyte development. Plant Cell 2004, 16(Suppl):S133-141 
3. Weterings K, Russell SD: Experimental analysis of the fertilization process. Plant Cell 2004, 16(Suppl):S107-118.

4. Berger F: Endosperm development. Curr Opin Plant Biol 1999, 2(1):28-32.

5. Olsen O-A: Endosperm development: cellularization and cell fate specification. Annu Rev Plant Physiol Plant Mol Biol 2001, 52(1):233-267.

6. Berger F: Endosperm: the crossroad of seed development. Curr Opin Plant Biol 2003, 6(1):42-50.

7. Bemer M, Wolters-Arts M, Grossniklaus U, Angenent GC: The MADS domain protein DIANA acts together with AGAMOUS-LIKE80 to specify the central cell in Arabidopsis ovules. Plant Cell 2008, 20(8):2088-2101.

8. Portereiko MF, Lloyd A, Steffen JG, Punwani JA, Otsuga D, Drews GN: AGL80 is required for central cell and endosperm development in Arabidopsis. Plant Cell 2006, 18(8):1862-1872.

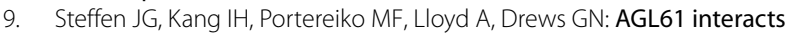
with AGL80 and is required for central cell development in Arabidopsis. Plant Physiol 2008, 148(1):259-268.

10. Grini PE, Jurgens G, Hulskamp M: Embryo and endosperm development is disrupted in the female gametophytic capulet mutants of Arabidopsis. Genetics 2002, 162(4):1911-1925.

11. Springer PS, Holding DR, Groover A, Yordan C, Martienssen RA: The essential Mcm7 protein PROLIFERA is localized to the nucleus of dividing cells during the $G(1)$ phase and is required maternally for early Arabidopsis development. Development 2000, 127(9):1815-1822.

12. Choi Y, Gehring M, Johnson L, Hannon M, Harada JJ, Goldberg RB, Jacobsen SE, Fischer RL: DEMETER, a DNA glycosylase domain protein, is required for endosperm gene imprinting and seed viability in Arabidopsis. Cell 2002, 110(1):33-42.

13. Grossniklaus U, Vielle-Calzada JP, Hoeppner MA, Gagliano WB: Maternal control of embryogenesis by MEDEA, a polycomb group gene in Arabidopsis. Science 1998, 280(5362):446-450.

14. Kiyosue T, Ohad N, Yadegari R, Hannon M, Dinneny J, Wells D, Katz A, Margossian L, Harada JJ, Goldberg RB, et al: Control of fertilizationindependent endosperm development by the MEDEA polycomb gene in Arabidopsis. Proc Natl Acad Sci USA 1999, 96(7):4186-4191.

15. Kohler C, Hennig L, Bouveret R, Gheyselinck J, Grossniklaus U, Gruissem W: Arabidopsis MSI1 is a component of the MEA/FIE Polycomb group complex and required for seed development. EMBOJ 2003, 22(18):4804-4814

16. Luo M, Bilodeau P, Koltunow A, Dennis ES, Peacock WJ, Chaudhury AM: Genes controlling fertilization-independent seed development in Arabidopsis thaliana. Proc Natl Acad Sci USA 1999, 96(1):296-301.

17. Ohad N, Margossian L, Hsu YC, Williams C, Repetti P, Fischer RL: A mutation that allows endosperm development without fertilization. Proc Natl Acad Sci USA 1996, 93(11):5319-5324.

18. Ohad N, Yadegari R, Margossian L, Hannon M, Michaeli D, Harada JJ, Goldberg RB, Fischer RL: Mutations in FIE, a WD polycomb group gene, allow endosperm development without fertilization. Plant Cell 1999, 11(3):407-416

19. Wang D, Tyson MD, Jackson SS, Yadegari R: Partially redundant functions of two SET-domain polycomb-group proteins in controlling initiation of seed development in Arabidopsis. Proc Natl Acad Sci USA 2006, 103(35):13244-13249.

20. Kagi C, Gross-Hardt R: How females become complex: cell differentiation in the gametophyte. Curr Opin Plant Bio/ 2007, 10(6):633-638

21. Higashiyama T, Yabe S, Sasaki N, Nishimura Y, Miyagishima S, Kuroiwa H, Kuroiwa T: Pollen tube attraction by the synergid cell. Science 2001, 293(5534):1480-1483.

22. Kasahara RD, Portereiko MF, Sandaklie-Nikolova L, Rabiger DS, Drews GN MYB98 is required for pollen tube guidance and synergid cell differentiation in Arabidopsis. Plant Cell 2005, 17(11):2981-2992.

23. Marton ML, Cordts S, Broadhvest J, Dresselhaus T: Micropylar pollen tube guidance by egg apparatus 1 of maize. Science 2005, 307(5709):573-576

24. Okuda S, Tsutsui H, Shiina K, Sprunck S, Takeuchi H, Yui R, Kasahara RD, Hamamura Y, Mizukami A, Susaki D, et al:: Defensin-like polypeptide LUREs are pollen tube attractants secreted from synergid cells. Nature 2009, 458(7236):357-361.

25. Punwani JA, Rabiger DS, Drews GN: MYB98 positively regulates a battery of synergid-expressed genes encoding filiform apparatus-localized proteins. Plant Cell 2007, 19(8):2557-2568.
26. Punwani JA, Rabiger DS, Lloyd A, Drews GN: The MYB98 subcircuit of the synergid gene regulatory network includes genes directly and indirectly regulated by MYB98. Plant J 2008, 55(3):406-414

27. Capron A, Gourgues M, Neiva LS, Faure JE, Berger F, Pagnussat G, Krishnan A, Alvarez-Mejia C, Vielle-Calzada JP, Lee YR, et al:: Maternal control of male-gamete delivery in Arabidopsis involves a putative GPI-anchored protein encoded by the LORELEI gene. Plant Cell 2008, 20(11):3038-3049

28. Escobar-Restrepo JM, Huck N, Kessler S, Gagliardini V, Gheyselinck J, Yang WC, Grossniklaus U: The FERONIA receptor-like kinase mediates malefemale interactions during pollen tube reception. Science 2007, 317(5838):656-660

29. Huck N, Moore JM, Federer M, Grossniklaus U: The Arabidopsis mutant feronia disrupts the female gametophytic control of pollen tube reception. Development 2003, 130(10):2149-2159.

30. Rotman N, Gourgues M, Guitton A-E, Faure JE, Berger F: A dialogue between the sirene pathway in synergids and the fertilization independent seed pathway in the central cell controls male gamete release during double fertilization in Arabidopsis. Mol Plant 2008, 1(4):659-666.

31. Rotman N, Rozier F, Boavida L, Dumas C, Berger F, Faure JE: Female control of male gamete delivery during fertilization in Arabidopsis thaliana. Curr Biol 2003, 13(5):432-436.

32. Maheshwari P: An introduction to the embryology of angiosperms. New York: McGraw-Hill Book Co; 1950.

33. Levine M, Davidson EH: Gene regulatory networks for development. Proc Natl Acad Sci USA 2005, 102(14):4936-4942.

34. Moll C, von Lyncker L, Zimmermann S, Kagi C, Baumann N, Twell D, Grossniklaus U, Gross-Hardt R: CLO/GFA1 and ATO are novel regulators of gametic cell fate in plants. Plant $J$ 2008, 56(6):913-921.

35. Liu M, Yuan L, Liu NY, Shi DQ, Liu J, Yang WC: GAMETOPHYTIC FACTOR1, involved in pre-mRNA splicing, is essential for megagametogenesis and embryogenesis in Arabidopsis. J Integr Plant Biol 2009, 51(3):261-271

36. Coury DA, Zhang C, Ko A, Skaggs MI, Christensen CA, Drews GN, Feldmann KA, Yadegari R: Segregation distortion in Arabidopsis gametophytic factor 1 (gfa1) mutants is caused by a deficiency of an essential RNA splicing factor. Sex Plant Reprod 2007, 20(2):87-97.

37. Kim HU, Li Y, Huang AH: Ubiquitous and endoplasmic reticulum-located lysophosphatidyl acyltransferase, LPAT2, is essential for female but not male gametophyte development in Arabidopsis. Plant Cell 2005, 17(4):1073-1089.

38. Gallois JL, Guyon-Debast A, Lecureuil A, Vezon D, Carpentier V Bonhomme S, Guerche P: The Arabidopsis proteasome RPT5 subunits are essential for gametophyte development and show accessiondependent redundancy. Plant Cell 2009, 21(2):442-459.

39. Kwee HS, Sundaresan V: The NOMEGA gene required for female gametophyte development encodes the putative APC6/CDC16 component of the Anaphase Promoting Complex in Arabidopsis. Plant J 2003, 36(6):853-866.

40. Shi DQ, Liu J, Xiang YH, Ye D, Sundaresan V, Yang WC: SLOW WALKER1, essential for gametogenesis in Arabidopsis, encodes a WD40 protein involved in $18 \mathrm{~S}$ ribosomal RNA biogenesis. Plant Cell 2005, 17(8):2340-2354.

41. Blanvillain R, Boavida LC, McCormick S, Ow DW: Exportin1 genes are essential for development and function of the gametophytes in Arabidopsis thaliana. Genetics 2008, 180(3):1493-1500.

42. Huanca-Mamani W, Garcia-Aguilar M, Leon-Martinez G, Grossniklaus U, Vielle-Calzada JP: CHR11, a chromatin-remodeling factor essential for nuclear proliferation during female gametogenesis in Arabidopsis thaliana. Proc Natl Acad Sci USA 2005, 102(47):17231-17236.

43. Colombo M, Masiero S, Vanzulli S, Lardelli P, Kater MM, Colombo L: AGL23, a type I MADS-box gene that controls female gametophyte and embryo development in Arabidopsis. Plant J 2008, 54(6):1037-1048.

44. Pagnussat GC, Yu HJ, Ngo QA, Rajani S, Mayalagu S, Johnson CS, Capron A, Xie LF, Ye D, Sundaresan V: Genetic and molecular identification of genes required for female gametophyte development and function in Arabidopsis. Development 2005, 132(3):603-614

45. Cordts S, Bantin J, Wittich PE, Kranz E, Lorz H, Dresselhaus T: ZmES genes encode peptides with structural homology to defensins and are specifically expressed in the female gametophyte of maize. Plant $J$ 2001, 25(1):103-114. 
46. Dresselhaus T, Amien S, Marton M, Strecke A, Brettschneider R, Cordts S: TRANSPARENT LEAF AREA1 encodes a secreted proteolipid required for anther maturation, morphogenesis, and differentiation during leaf development in maize. Plant Cell 2005, 17(3):730-745.

47. Dresselhaus T, Cordts S, Lorz H: A transcript encoding translation initiation factor elF-5A is stored in unfertilized egg cells of maize. Plant Mol Biol 1999, 39(5):1063-1071.

48. Dresselhaus T, Lorz H, Kranz E: Representative cDNA libraries from few plant cells. Plant J 1994, 5(4):605-610.

49. Kumlehn J, Kirik V, Czihal A, Altschmied L, Matzk F, Lorz H, Baumlein H: Parthenogenetic egg cells of wheat: cellular and molecular studies. Sex Plant Reprod 2001, 14(4):239-243.

50. Le Q, Gutierrez-Marcos JF, Costa LM, Meyer S, Dickinson HG, Lorz H, Kranz E, Scholten S: Construction and screening of subtracted cDNA libraries from limited populations of plant cells: a comparative analysis of gene expression between maize egg cells and central cells. Plant J 2005, 44(1):167-178

51. Ning J, Peng XB, Qu LH, Xin HP, Yan TT, Sun M: Differential gene expression in egg cells and zygotes suggests that the transcriptome is restructed before the first zygotic division in tobacco. FEBS Lett 2006, 580(7):1747-1752

52. Sprunck S, Baumann U, Edwards K, Langridge P, Dresselhaus T: The transcript composition of egg cells changes significantly following fertilization in wheat (Triticum aestivum L.). Plant J 2005, 41(5):660-672

53. Yang H, Kaur N, Kiriakopolos S, McCormick S: EST generation and analyses towards identifying female gametophyte-specific genes in Zea mays L. Planta 2006, 224(5):1004-1014.

54. Johnston AJ, Meier P, Gheyselinck J, Wuest SE, Federer M, Schlagenhauf E, Becker JD, Grossniklaus U: Genetic subtraction profiling identifies genes essential for Arabidopsis reproduction and reveals interaction between the female gametophyte and the maternal sporophyte. Genome Biol 2007, 8(10):R204.

55. Jones-Rhoades MW, Borevitz JO, Preuss D: Genome-wide expression profiling of the Arabidopsis female gametophyte identifies families of small, secreted proteins. PLoS Genet 2007, 3(10):1848-1861.

56. Steffen JG, Kang IH, Macfarlane J, Drews GN: Identification of genes expressed in the Arabidopsis female gametophyte. Plant J 2007, 51(2):281-292.

57. Yu HJ, Hogan P, Sundaresan V: Analysis of the female gametophyte transcriptome of Arabidopsis by comparative expression profiling. Plant Physiol 2005, 139(4):1853-1869.

58. Yang WC, Ye D, Xu J, Sundaresan V: The SPOROCYTELESS gene of Arabidopsis is required for initiation of sporogenesis and encodes a novel nuclear protein. Genes Dev 1999, 13(16):2108-2117.

59. Bai X, Peirson BN, Dong F, Xue C, Makaroff CA: Isolation and characterization of SYN1, a RAD21-like gene essential for meiosis in Arabidopsis. Plant Cell 1999, 11(3):417-430.

60. Bhatt AM, Lister C, Page T, Fransz P, Findlay K, Jones GH, Dickinson HG, Dean C: The DIF1 gene of Arabidopsis is required for meiotic chromosome segregation and belongs to the REC $8 / R A D 21$ cohesin gene family. Plant J 1999, 19(4):463-472.

61. Vaquerizas JM, Kummerfeld SK, Teichmann SA, Luscombe NM: A census of human transcription factors: function, expression and evolution. Nat Rev Genet 2009, 10(4):252-263.

62. Holland MJ: Transcript abundance in yeast varies over six orders of magnitude. J Biol Chem 2002, 277(17):14363-14366.

63. Christensen CA, King EJ, Jordan JR, Drews GN: Megagametogenesis in Arabidopsis wild type and the Gf mutant. Sex Plant Reprod 1997 10(1):49-64

64. Cai X, Dong F, Edelmann RE, Makaroff CA: The Arabidopsis SYN1 cohesin protein is required for sister chromatid arm cohesion and homologous chromosome pairing. J Cell Sci 2003, 116(14):2999-3007.

65. Ito T, Shinozaki K: The MALE STERILITY1 gene of Arabidopsis, encoding a nuclear protein with a PHD-finger motif, is expressed in tapetal cells and is required for pollen maturation. Plant Cell Physiol 2002, 43(11):1285-1292.

66. Thorlby GJ, Shlumukov L, Vizir IY, Yang CY, Mulligan BJ, Wilson ZA: Finescale molecular genetic (RFLP) and physical mapping of a $8.9 \mathrm{cM}$ region on the top arm of Arabidopsis chromosome 5 encompassing the male sterility gene, ms1. Plant J 1997, 12(2):471-479.

67. Wilson ZA, Morroll SM, Dawson J, Swarup R, Tighe PJ: The Arabidopsis MALE STERILITY1 (MS1) gene is a transcriptional regulator of male gametogenesis, with homology to the PHD-finger family of transcription factors. Plant J 2001, 28(1):27-39.

68. Smyth DR, Bowman JL, Meyerowitz EM: Early flower development in Arabidopsis. Plant Cell 1990, 2(8):755-767.

69. Boisnard-Lorig C, Colon-Carmona A, Bauch M, Hodge S, Doerner P, Bancharel E, Dumas C, Haseloff J, Berger F: Dynamic analyses of the expression of the HISTONE::YFP fusion protein in Arabidopsis show that syncytial endosperm is divided in mitotic domains. Plant Cell 2001, 13(3):495-509.

70. Kanda T, Sullivan KF, Wahl GM: Histone-GFP fusion protein enables sensitive analysis of chromosome dynamics in living mammalian cells. Curr Biol 1998, 8(7):377-385.

71. Olsen O-A: Nuclear endosperm development in cereals and Arabidopsis thaliana. Plant Cell 2004, 16(Suppl):S214-227.

72. Kondou Y, Nakazawa M, Kawashima M, Ichikawa T, Yoshizumi T, Suzuki K Ishikawa A, Koshi T, Matsui R, Muto S, et al.: RETARDED GROWTH OF EMBRYO1, a new basic helix-loop-helix protein, expresses in endosperm to control embryo growth. Plant Physiol 2008 147(4):1924-1935.

73. Yang S, Johnston N, Talideh E, Mitchell S, Jeffree C, Goodrich J, Ingram G: The endosperm-specific ZHOUPI gene of Arabidopsis thaliana regulates endosperm breakdown and embryonic epidermal development. Development 2008, 135(21):3501-3509.

74. Baxter CE, Costa MM, Coen ES: Diversification and co-option of RAD-like genes in the evolution of floral asymmetry. Plant J 2007, 52(1):105-113.

75. Day RC, Herridge RP, Ambrose BA, Macknight RC: Transcriptome analysis of proliferating Arabidopsis endosperm reveals biological implications for the control of syncytial division, cytokinin signaling, and gene expression regulation. Plant Physiol 2008, 148(4):1964-1984.

76. Luo M, Dennis ES, Berger F, Peacock WJ, Chaudhury A: MINISEED3 (MINI3), a WRKY family gene, and HAIKU2 (IKU2), a leucine-rich repeat (LRR) KINASE gene, are regulators of seed size in Arabidopsis. Proc Nat/ Acad SCiUSA 2005, 102(48):17531-17536.

77. Finkelstein RR, Wang ML, Lynch TJ, Rao S, Goodman HM: The Arabidopsis abscisic acid response locus ABI4 encodes an APETALA 2 domain protein. Plant Cell 1998, 10(6):1043-1054.

78. Acevedo-Hernandez GJ, Leon P, Herrera-Estrella LR: Sugar and ABA responsiveness of a minimal $\mathrm{RBCS}$ light-responsive unit is mediated by direct binding of ABI4. Plant J 2005, 43(4):506-519.

79. Bossi F, Cordoba E, Dupre P, Mendoza MS, Roman CS, Leon P: The Arabidopsis ABA-INSENSITIVE (ABI) 4 factor acts as a central transcription activator of the expression of its own gene, and for the induction of $A B 15$ and SBE2.2 genes during sugar signaling. Plant J 2009, 59(3):359-374

80. Haecker A, Gross-Hardt R, Geiges B, Sarkar A, Breuninger H, Herrmann M, Laux T: Expression dynamics of WOX genes mark cell fate decisions during early embryonic patterning in Arabidopsis thaliana. Development 2004, 131(3):657-668

81. Breuninger $H$, Rikirsch $E_{1}$ Hermann $M$, Ueda M, Laux T: Differential expression of WOX genes mediates apical-basal axis formation in the Arabidopsis embryo. Dev Cell 2008, 14(6):867-876

82. Wu X, Chory J, Weigel D: Combinations of WOX activities regulate tissue proliferation during Arabidopsis embryonic development. Dev Biol 2007, 309(2):306-316.

83. Lotan T, Ohto M, Yee KM, West MA, Lo R, Kwong RW, Yamagishi K, Fischer $\mathrm{RL}$, Goldberg RB, Harada JJ: Arabidopsis LEAFY COTYLEDON1 is sufficient to induce embryo development in vegetative cells. Cell 1998, 93(7):1195-1205.

84. Kotak S, Vierling E, Baumlein H, von Koskull-Doring P: A novel transcriptional cascade regulating expression of heat stress proteins during seed development of Arabidopsis. Plant Cell 2007, 19(1):182-195

85. Ingouff M, Jullien PE, Berger F: The female gametophyte and the endosperm control cell proliferation and differentiation of the seed coat in Arabidopsis. Plant Cell 2006, 18(12):3491-3501.

86. Pagnussat GC, Alandete-Saez M, Bowman JL, Sundaresan V: Auxindependent patterning and gamete specification in the Arabidopsis female gametophyte. Science 2009, 324(5935):1684-1689.

87. Englbrecht CC, Schoof H, Bohm S: Conservation, diversification and expansion of $\mathrm{C} 2 \mathrm{H} 2$ zinc finger proteins in the Arabidopsis thaliana genome. BMC Genomics 2004, 5(1):39. 
88. Soderman EM, Brocard IM, Lynch TJ, Finkelstein RR: Regulation and function of the Arabidopsis $A B A$-insensitive 4 gene in seed and abscisic acid response signaling networks. Plant Physio/ 2000, 124(4):1752-1765.

89. Arroyo A, Bossi F, Finkelstein RR, Leon P: Three genes that affect sugar sensing (abscisic acid insensitive 4, abscisic acid insensitive 5, and constitutive triple response 1) are differentially regulated by glucose in Arabidopsis. Plant Physiol 2003, 133(1):231-242.

90. Kagaya Y, Toyoshima R, Okuda R, Usui H, Yamamoto A, Hattori T: LEAFY COTYLEDON1 controls seed storage protein genes through its regulation of FUSCA3 and ABSCISIC ACID INSENSITIVE3. Plant Cell Physiol 2005, 46(3):399-406.

91. Yamamoto A, Kagaya Y, Toyoshima R, Kagaya M, Takeda S, Hattori T: Arabidopsis NF-YB subunits LEC1 and LEC1-LIKE activate transcription by interacting with seed-specific ABRE-binding factors. Plant J 2009, 58(5):843-856.

92. Bhatt AM, Page T, Lawson EJ, Lister C, Dean C: Use of Ac as an insertional mutagen in Arabidopsis. Plant J 1996, 9(6):935-945.

93. Czechowski T, Bari RP, Stitt M, Scheible WR, Udvardi MK: Real-time RT-PCR profiling of over 1400 Arabidopsis transcription factors: unprecedented sensitivity reveals novel root- and shoot-specific genes. Plant J 2004, 38(2):366-379

94. Davuluri RV, Sun H, Palaniswamy SK, Matthews N, Molina C, Kurtz M, Grotewold E: AGRIS: Arabidopsis gene regulatory information server, an information resource of Arabidopsis cis-regulatory elements and transcription factors. BMC Bioinformatics 2003, 4:25

95. Palaniswamy SK, James S, Sun H, Lamb RS, Davuluri RV, Grotewold E: AGRIS and AtRegNet. a platform to link cis-regulatory elements and transcription factors into regulatory networks. Plant Physiol 2006, 140(3):818-829.

96. Guo A, He K, Liu D, Bai S, Gu X, Wei L, Luo J: DATF: a database of Arabidopsis transcription factors. Bioinformatics 2005, 21(10):2568-2569.

97. Livak KJ, Schmittgen TD: Analysis of relative gene expression data using real-time quantitative PCR and the 2(-Delta Delta C(T)) Method. Methods 2001, 25(4):402-408.

98. Yadegari R, Kinoshita T, Lotan O, Cohen G, Katz A, Choi Y, Nakashima K Harada JJ, Goldberg RB, Fischer RL, et al: Mutations in the FIE and MEA genes that encode interacting polycomb proteins cause parent-oforigin effects on seed development by distinct mechanisms. Plant Cell 2000, 12(12):2367-2382.

99. Yolov AA, Shabarova ZA: Constructing DNA by polymerase recombination. Nucleic Acids Res 1990, 18(13):3983-3986.

100. Yon J, Fried M: Precise gene fusion by PCR. Nucleic Acids Res 1989, 17(12):4895..

101. Koncz C, Schell J: The promoter of $\mathrm{T}_{\mathrm{L}}$-DNA gene 5 controls the tissuespecific expression of chimaeric genes carried by a novel type of Agrobacterium binary vector. Mol Genet Genomics 1986 204(3):383-396.

102. Hoekema A, Hirsch PR, Hooykaas PJJ, Schilperoort RA: A binary plant vector strategy based on separation of vir- and T-region of the Agrobacterium tumefaciens Ti-plasmid. Nature 1983, 303(5913):179-180.

103. Clough SJ, Bent AF: Floral dip: a simplified method for Agrobacteriummediated transformation of Arabidopsis thaliana. Plant J 1998, 16(6):735-743

104. Brown RC, Lemmon BE, Nguyen H, Olsen O-A: Development of endosperm in Arabidopsis thaliana. Sex Plant Reprod 1999, 12(1):32-42.

doi: 10.1186/1471-2229-10-110

Cite this article as: Wang et al., Identification of transcription-factor genes expressed in the Arabidopsis female gametophyte BMC Plant Biology 2010 $10: 110$

\section{Submit your next manuscript to BioMed Centra} and take full advantage of:

- Convenient online submission

- Thorough peer review

- No space constraints or color figure charges

- Immediate publication on acceptance

- Inclusion in PubMed, CAS, Scopus and Google Scholar

- Research which is freely available for redistribution

Submit your manuscript at www biomedcentral com/submit
C Biomed Central 